\title{
The efficacy and safety of anti-PD-1/PD-L1 antibodies for treatment of advanced or refractory cancers: a meta-analysis
}

\author{
Tengfei Zhang ${ }^{1,2, *}$, Jing $\mathrm{Xie}^{3, *}$, Seiji Araii,4, Liping Wang ${ }^{5}$, Xuezhong Shi ${ }^{6}, \mathrm{Ni}^{2} \mathrm{Shi}^{7}$, \\ Fen $\mathrm{Ma}^{2}$, Sen Chen ${ }^{2}$, Lan Huang${ }^{1}$, Li Yang${ }^{1}$, Wang Ma ${ }^{5}$, Bin Zhang ${ }^{8}$, Weidong Han', \\ Jianchuan Xia ${ }^{10}$, Hu Chen ${ }^{8}$, Yi Zhang ${ }^{1,5,11,12}$ \\ ${ }^{1}$ Biotherapy Center, Cancer Center, The First Affiliated Hospital of Zhengzhou University, Zhengzhou, Henan, China \\ ${ }^{2}$ Department of Hematology and Oncology, Beth Israel Deaconess Medical Center, Harvard Medical School, Boston, \\ Massachusetts, United States \\ ${ }^{3}$ School of Public Health, Xinxiang Medical University, Xinxiang, Henan, China \\ ${ }^{4}$ Department of Urology, Gunma University Graduate School of Medicine, 3-39-22 Showa-machi, Maebashi, Japan \\ ${ }^{5}$ Department of Oncology, the First Affiliated Hospital of Zhengzhou University, Zhengzhou, Henan, China \\ ${ }^{6}$ Department of Epidemiology and Biostatistics, School of Public Health, Zhengzhou University, Zhengzhou, Henan, China \\ ${ }^{7}$ Comprehensive Cancer Center, the Ohio State University, Columbus, Ohio, United States \\ ${ }^{8}$ Department of Hematopoietic Stem Cell Transplantation, Affiliated Hospital to Academy of Military Medical Science (307 \\ Hospital, PLA), Beijing, China \\ ${ }^{9}$ Molecular and Immunological/Bio-therapeutic Department, Institute of Basic Medicine, Chinese PLA General Hospital, \\ Beijing China \\ ${ }^{10}$ Biotherapy Center, Cancer Center, Sun Yat-sen University, Guangzhou, Guangzhou, Guangdong, China \\ ${ }^{11}$ Henan Key Laboratory for Tumor Immunology and Biotherapy, Henan, China \\ ${ }^{12}$ School of Life Sciences, Zhengzhou University, Zhengzhou, Henan, China \\ *These authors contributed equally to this work
}

Correspondence to: Yi Zhang, email: yizhang@zzu.edu.cn Hu Chen, email: chenhu217@aliyun.com

Keywords: $P D-1, P D-L 1$, immunotherapy, advanced or refractory cancer, meta-analysis

Received: May 27, $2016 \quad$ Accepted: September 17, $2016 \quad$ Published: September 24, 2016

\section{ABSTRACT}

Purpose: To systematically evaluate the overall efficacy and safety of current anti-PD-1/PD-L1 antibodies for treatment of patients with advanced or refractory cancer.

Results: Fifty-one trials including 6,800 patients were included. The overall response rates for melanoma, non-small cell lung cancer (NSCLC), and renal cell carcinoma (RCC) were 29\% (95\% CI: 1.53-2.41), 21\% (95\% CI: $17 \%-25 \%$ ) and $21 \%(95 \%$ CI: $16 \%-27 \%)$ respectively. While the overall adverse effects rate for melanoma, NSCLC, RCC were 16\% (95\% CI: 6\%-28\%), 11\% (95\% CI: $8 \%-14 \%$ ) and $20 \%(95 \%$ CI: $11 \%-32 \%)$ respectively. Tumor PD-L1 expression and patient smoking status might serve as biomarkers to predict response of anti-PD-1/PD-L1 antibody treatment. Compared to tumors with negative PD-L1 expression, tumors with positive PD-L1 expression had a significantly higher clinical response rate $(41.4 \%$ versus $26.5 \%)$ with $R R=1.92(95 \% C I$ : $1.53-2.41, P<0.001)$. Smoker patients also showed a significantly higher response rate $(33.7 \%)$ than patients who never smoked (4.2\%) with RR = 6.02 (95\% CI: 1.22-29.75, $P=0.028)$. Nivolumab and Pembrolizumab were associated with significantly increased response rate $(R R=2.89$, 95\% CI: 2.46-3.40, $P<0.001$ ), reduced death risk (HR= 0.53; 95\% CI: $0.48-0.57$; $P<0.001)$, and decreased adverse effect rate ( $R R=0.49,95 \%$ CI: $0.30-0.80$, $P=0.004)$ compared with other therapies.

Experimental Design: Clinical trials reporting response or safety of anti-PD-1/ PD-L1 antibodies for advanced or refractory cancer patients published before January 


\section{1th 2016 were searched in PubMed and EMBASE database. Meta-analyses using random effects models were used to calculate the overall estimate. Conclusions: Anti-PD-1/PD-L1 antibodies have high response rates and low adverse effect rates for advanced or refractory cancers.}

\section{INTRODUCTION}

Cancer is still one of the most pressing health issues worldwide [1]. Although surgery, radiation and chemotherapy have significantly improved the clinical benefits for patients with localized cancer, therapies for advanced or refractory cancer patients still present a challenge [2]. Patients with advanced cancer usually miss the opportunity for surgery due to late diagnosis. Because of the diversities of genetic and epigenetic mutations harbored by cancer cells, a subpopulation of those patients rarely benefit from conventional systematic chemotherapy $[2,3]$. In addition, immune evasion by cancer cells that spoil the initiation of effective antitumor response in cancer microenvironment inevitably presents problems for treatment of advanced and refractory cancer patients $[3,4]$. However, endogenous immune response generated by "immune checkpoint" inhibitors was beneficial for cancer regression. The persistent immune response and effective immunologic memory might also have enabled the sustained control of tumor growth. Therefore immunotherapy, especially immunotherapy based on "immune checkpoint" inhibitors, showed broad advantages with durable clinical responses for advanced or refractory cancer patients [5].

Programmed death 1 (PD-1) is a highly expressed immune checkpoint receptor in immune lymphocytes. PD-1 is normally required for limiting autoimmunity and modulating the strength of $\mathrm{T}$ cell response in peripheral infected tissues in order to minimize damage to surrounding normal tissues $[5,6]$. This inhibitory effect on immune activation is executed by the interaction of PD-1 with its ligand PD-L1. Importantly, PD-1 is highly expressed on tumor-infiltrating lymphocytes, whereas PD-L1 is upregulated in many human cancer cells so that cancers can escape from the immunologic surveillance by suppressing the immune function of $\mathrm{T}$ cells [7]. Therefore, antibodies against PD-1 and PD-L1 are promising therapies since they can reactivate the patient's own immune system, especially lymphocytes in tumor microenvironment, to fight against cancers by maintaining $\mathrm{T}$ cell activation.

Clinical trials have shown that anti-PD-1 antibodies Pembrolizumab and Nivolumab had promising overall response rate and prolonged survival for advanced or refractory melanoma patients $[8,9]$. In one of the Pembrolizumab trial, the overall response rate was $26 \%$ and the estimated overall survival at 1 year was $63 \%$ in patients who received $10 \mathrm{mg} / \mathrm{kg}$ Pembrolizumab
[8]. In another randomized open-label trial to compare Nivolumab with chemotherapy, the overall response rate was $31.7 \%$ in the Nivolumab group, compared to $10.6 \%$ in the chemotherapy group [9]. Therefore, the US Food and Drug Administration approved them for treatment of patients with unresectable or metastatic melanoma and disease progression following Ipilimumab (antiCTL4 antibody), and for B-Raf proto-oncogene, serine/ threonine kinase (BRAF) V600 mutation-positive patients with a BRAF inhibitor respectively. The improved response and prolonged survival of anti-PD-1/PD-L1 antibodies were also supported by other trials for patients with metastatic non-small cell lung cancer (NSCLC), hematological malignancies, renal cell cancer (RCC), bladder cancer, colon cancer and some other cancers [10-20]. However, systematic evaluation of the overall efficiency of anti-PD-1/PD-L1 antibodies for advanced or refractory cancer patients was limited. The published studies only summarized data for one or few types of cancers [21, 22]. Moreover, the key factors associated with better clinical responses still remain unclear. Thus, we will systematically evaluate the efficiency and safety of current clinical anti-PD-1/PD-L1 antibodies for advanced or refractory cancers and use this data to investigate potential factors associated with clinical responses. This study will present comprehensive data and evidence for future clinical application of anti-PD-1/PD-L1 antibodies based on current clinical trials.

\section{RESULTS}

\section{Summary of included studies}

After removing duplicated literatures, unrelated literatures and some ineligible literatures, two investigators identified articles eligible for further review by screening titles and abstracts. We identified 33 literatures and 18 conference abstracts with a total of 6,800 patients involved (Figure 1). Both solid cancer patients and hematologic malignancy patients participated in these trials. Within these trials, data of 6,160 patients were used for efficiency analysis and and 6,273 patients for safety analysis. All the patients that received PD-1/ PD-L1 antibodies were in advanced stages and most of the patients received previous treatment. The antibodies used in these trials included the anti-PD-1 antibodies Nivolumab, Pidilizumab and Pembrolizumab; and the anti-PD-L1 antibodies: BMS-936559, MPDL3280A and Avelumab. All the information of the clinical trials is listed 
in Supplementary Table S1. Literature quality assessment by MINORS showed that literatures recruited in this study were in good quality (Supplementary Table S2).

\section{Overall response rate}

Meta-analysis showed that the overall pooled response rates of anti-PD-1/PD-L1 antibodies was $24 \%(95 \%$ CI: $21 \%-28 \%)$ in cancer patients with advanced stage, refractory or sensitive to previous treatment (Table 1 and Supplementary Figure S1A). Egger's regression asymmetry test $(P=0.105)$ showed no evidence of substantial publication bias and the funnel plot is listed in Supplementary Figure S2. Univariate meta-regression analysis showed that NSCLC, combination and antigen origin positively associated with anti-PD-1/PD-L1 antibody responses. Subgroup analyses also pooled the response rate for each drug and tumors (Table 1, Supplementary Figure S1B and S1C). The FDA approved anti-PD-1 antibodies, Nivolumab and Pembrolizumab showed promising response rates at $27 \%$ (95\% CI: $21 \%-33 \%$, $\mathrm{Z}=14.61, P<0.001)$ and $26 \%(95 \% \mathrm{CI}: 21 \%-31 \%$,
$\mathrm{Z}=15.64, P<0.001)$ respectively. The pooled response rates for melanoma, NSCLC, RCC were $29 \%(95 \% \mathrm{CI}$ : $23 \%-36 \%, Z=14.70, P<0.001), 21 \%$ (95\% CI: $17 \%-25 \%$, $\mathrm{Z}=16.16, P<0.001)$ and $21 \%(95 \% \mathrm{CI}: 16 \%-27 \%$, $\mathrm{Z}=11.88, P<0.001)$ respectively.

\section{Anti-PD-1/PD-L1 antibodies have higher clinical response rates than regular chemotherapy and Ipilimumab in melanoma patients}

We compared the response rates of anti/PD-1/ PD-L1 antibodies (Nivolumab and Pembrolizumab) with other regular chemotherapy and Ipilimumab in melanoma patients (6 studies, details see Supplementary Table S1). We found that anti-PD-1/PD-L1 antibodies were associated with a significant increase in the response rates compared with other therapies $(\mathrm{RR}=2.89,95 \% \mathrm{CI}$ : 2.46-3.40, $P<0.001)$ with no evidence of heterogeneity $\left(I^{2}=0.00, \chi^{2}=4.17, P=0.525\right)$ (Figure 2A). Begg's regression asymmetry test $(P=0.06)$ showed no evidence of substantial publication bias. Compared to the control group, where 129 people out of 1000 had response events, 372 out of 1000 treated with the anti-PD-1/PD-L1

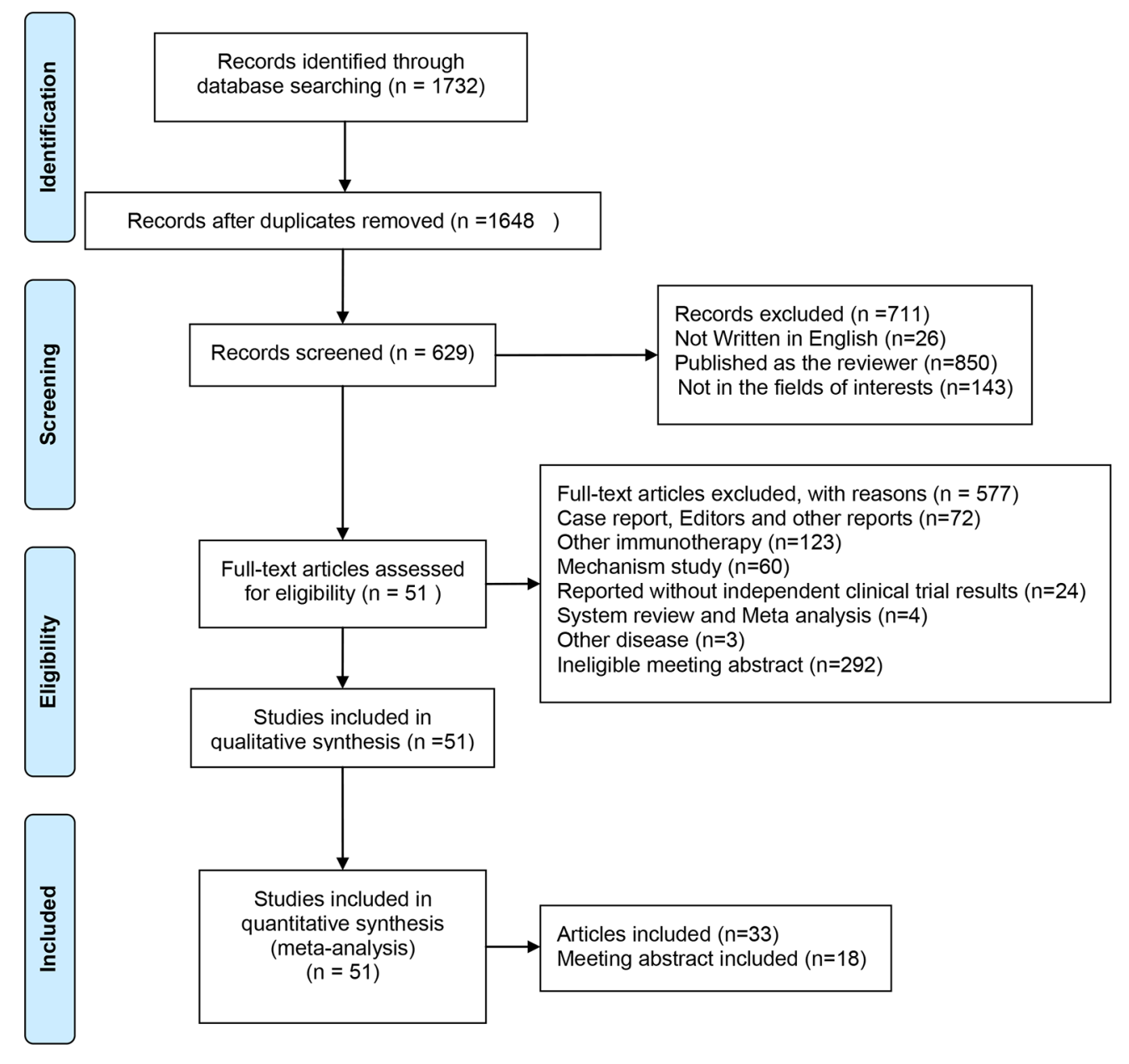

Figure 1: Flow diagram of study selection process. 
Table 1: Meta-regression analysis for response rates and adverse effect rates of anti-PD-1/PD-L1 antibodies in cancers

\begin{tabular}{|c|c|c|c|c|c|c|c|c|c|c|c|c|}
\hline \multirow{3}{*}{$\begin{array}{l}\text { Factors at } \\
\text { study level }\end{array}$} & \multicolumn{6}{|c|}{ Response rates } & \multicolumn{6}{|c|}{ Adverse effects rates } \\
\hline & \multirow[b]{2}{*}{$\begin{array}{l}\text { No. of } \\
\text { Data }^{\text {a }}\end{array}$} & \multirow{2}{*}{$\begin{array}{c}\text { Pooled Response } \\
\text { Rate } \\
(95 \% \text { CI })\end{array}$} & \multirow[b]{2}{*}{$I^{2}(\%)$} & \multirow[b]{2}{*}{$P$ for $I^{2}$} & \multicolumn{2}{|c|}{ Meta-regression analysis } & \multirow{2}{*}{$\begin{array}{l}\text { No. of } \\
\text { Data } \\
\text { * }\end{array}$} & \multirow{2}{*}{$\begin{array}{c}\text { Pooled Response } \\
\text { Rate } \\
(95 \% \text { CI })\end{array}$} & \multirow[b]{2}{*}{$I^{2}(\%)$} & \multirow[b]{2}{*}{$P$ for $I^{2}$} & \multicolumn{2}{|c|}{ Meta-regression analysis } \\
\hline & & & & & $\begin{array}{c}\text { Coefficients } \\
(95 \% \mathrm{CI})\end{array}$ & $P$ value & & & & & $\begin{array}{c}\text { Coefficients } \\
(95 \% \text { CI) }\end{array}$ & $P$ value \\
\hline \multicolumn{13}{|l|}{ Tumor type } \\
\hline Melanoma & 19 & $0.29(0.23,0.36)$ & 91.22 & $<0.001$ & 0 & & 13 & $0.16(0.06,0.28)$ & 97.97 & $<0.001$ & 0 & \\
\hline NSCLC & 14 & $0.21(0.17,0.25)$ & 73.51 & $<0.001$ & $-0.12(-0.20,-0.03)$ & 0.008 & 8 & $0.11(0.08,0.14)$ & 62.24 & 0.01 & $-0.07(-0.21,0.08)$ & 0.363 \\
\hline $\mathrm{RCC}$ & 9 & $0.21(0.16,0.27)$ & 73.00 & $<0.001$ & $-0.10(-0.21,-0.00)$ & 0.046 & 7 & $0.20(0.11,0.32)$ & 92.51 & $<0.001$ & $0.03(-0.13,0.18)$ & 0.708 \\
\hline $\begin{array}{l}\text { Hematologic } \\
\text { malignancies }\end{array}$ & 4 & $0.54(0.20,0.86)$ & 94.96 & $<0.001$ & $0.11(-0.07,0.29)$ & 0.230 & 4 & $0.30(0.03,0.69)$ & 94.71 & $<0.001$ & $0.19(-0.05,0.43)$ & 0.121 \\
\hline Ovarian cancer & 3 & $0 \cdot 14(0.07,0.24)$ & 0.000 & 0.85 & $-0.18(-0.44,0.08)$ & 0.163 & 2 & $0.16(0.06,0.29)$ & 98.43 & $<0.001$ & $0 \cdot 02(-0 \cdot 34,0.38)$ & 0.907 \\
\hline Bladder cancer & 2 & $0.26(0.17,0.35)$ & 0.000 & 0.57 & $-0.07(-0.31,0.17)$ & 0.560 & 2 & $0.09(0.04,0.15)$ & 98.75 & $<0.001$ & $-0.09(-0.38,0.20)$ & 0.525 \\
\hline Esophageal cancer & 1 & $0.22(0.07,0.44)$ & NA & NA & $-0.11(-0.55,0.33)$ & 0.619 & 1 & $0.26(0.10,0.48)$ & NA & NA & $0.08(-0.42,0.58)$ & 0.751 \\
\hline Mixed cancer ${ }^{\mathrm{b}}$ & 6 & $0.09(0.02,0.19)$ & 74.19 & $<0.001$ & $-0.22(-0.39,-0.06)$ & 0.009 & 6 & $0.14(0.06,0.24)$ & 92.14 & $<0.001$ & $-0.03(-0.20,0.13)$ & 0.702 \\
\hline \multicolumn{13}{|l|}{ Drug } \\
\hline Nivolumab & 28 & $0.27(0.21,0.33)$ & 92.39 & $<0.001$ & 0 & & 23 & $0.18(0.11,0.26)$ & 96.98 & $<0.001$ & 0 & \\
\hline Pembrolizumab & 14 & $0.26(0.21,0.31)$ & 75.04 & $<0.001$ & $-0.02(-0.11,0.07)$ & 0.954 & 11 & $0.09(0.06,0.14)$ & 81.36 & $<0.001$ & $-0.08(-0.21,0.05)$ & 0.204 \\
\hline MPDL3280A & 8 & $0.18(0.15,0.22)$ & 4.92 & 0.39 & $-0.10(-0.22,0.02)$ & 0.087 & 4 & $0.13(0.10,0.16)$ & 0.00 & 0.45 & $-0.06(-0.23,0.11)$ & 0.494 \\
\hline BMS-936559 & 4 & $0.10(0.03,0.18)$ & 51.17 & 0.10 & $-0.18(-0.37,0.01)$ & 0.056 & 4 & $0.31(0.03,0.70)$ & 94.61 & $<0.001$ & $0.19(-0.04,0.42)$ & 0.110 \\
\hline Pidilizumab & 3 & $0.37(0.03,0.82)$ & 96.70 & $<0.001$ & $0.01(-0.18,0.21)$ & 0.882 & 1 & $0.09(0.06,0.14)$ & NA & NA & $-0.10(-0.40,0.19)$ & 0.490 \\
\hline Avelumab & 1 & $0.17(0.05,0.39)$ & NA & NA & NA & NA & 1 & NA & NA & NA & NA & NA \\
\hline \multicolumn{13}{|l|}{ Combination } \\
\hline No Combination & 49 & $0.21(0.18,0.24)$ & 82.43 & $<0.001$ & 0 & \multirow{2}{*}{$<0.001$} & 35 & $0.13(0.10,0.16)$ & 86.94 & $<0.001$ & 0 & \multirow{2}{*}{$<0.001$} \\
\hline Combination & 9 & $0.41(0.32,0.51)$ & 85.66 & $<0.001$ & $-0.22(-0.30,-0.15)$ & & 8 & $0.29(0.14,0.46)$ & 95.30 & $<0.001$ & $0.29(0.18,0.40)$ & \\
\hline \multicolumn{13}{|l|}{ Antigen Origin } \\
\hline Anti-PD-L1 & 13 & $0.16(0.12,0.20)$ & 39.57 & 0.07 & 0 & 0.018 & 38 & $0.17(0.11,0.22)$ & 96.10 & $<0.001$ & 0 & 0.439 \\
\hline Anti-PD-1 & 45 & $0.27(0.23,0.31)$ & 90.83 & $<0.001$ & $-0.12(-0.22,-0.02)$ & & 5 & $0.12(0.09,0.15)$ & 24.51 & 0.26 & $-0.06(-0.21,0.09)$ & \\
\hline
\end{tabular}

Note: athe number of data set extracted from studies; 'Mix cancer: multiple tumors included in these four studies but can't be separately totally by tumor types.

antibodies had response cases. Based on a rate of $12.9 \%$, the NNTB would be 4 . Compared to other therapies, the number of response cases added per 1000 individuals by anti-PD-1/PD-L1 drugs was 243. Nivolumab alone was associated with a significant increase in the response rate compared to other therapies ( 4 studies, $\mathrm{RR}=2.83$, 95\% CI: 2.34-3.43, $P<0.001$ ), with no evidence of heterogeneity $\left(I^{2}=0.00, \chi^{2}=2.70, P=0.439\right)$. Pembrolizumab was also associated with a significant increase in the response rate compared to other therapies (2 studies, RR $=3.04,95 \% \mathrm{CI}: 2.24-4.13, P<0.001)$, with slight heterogeneity $\left(I^{2}=24.3, \chi^{2}=1.32, P=0.251\right.$, Supplementary Figure S1D). Moreover, these two antiPD-1 antibodies (Nivolumab and Pembrolizumab) substantially reduced the risk of death compared with other therapies ( 8 studies, $\mathrm{HR}=0.53$; $95 \% \mathrm{CI}$ : $0.48-0.57$; $P<0.001)$, with no evidence of heterogeneity $\left(I^{2}=0.00\right.$, $\chi^{2}=6.95, P=4.34$, Figure $2 \mathrm{~B}$ ).

\section{Potential biomarkers to predict clinical outcomes}

We evaluated the current reported factors that might potentially affect the clinical outcomes in different cancers. These potential factors include PD-L1 expression, tumor-infiltrating lymphocytes, gene mutation (BRAF,
EGFR, KRAS and DNA mismatch repair related genes), blood immune biomarkers (such as IL-18, ITAC, IFN- $\gamma$, IL-6) and patients' life style such as smoking history, etc. The details of these factors are listed in Table 2 .

Meta-analysis showed that PD-L1 positive patients had a significantly higher response rate than PD-L1 negative patients (20 studies, $\mathrm{RR}=1.92,95 \% \mathrm{CI}: 1.53-2.41$, $P<0.001)$ with mild heterogeneity $\left(I^{2}=56.9 \%, \chi^{2}=44.08\right.$, $P=0.001$ ) (Table 3 and Supplementary Figure S3A). Begg's test showed no evidence of substantial publication bias $(P=0.230)$. Compared to 265 out of 1000 people having response events in the PD-1 negative patients, 509 out of 1000 people had response cases in the PD-1 positive group. Based on a rate of $26.5 \%$ in the PD- 1 negative group, the NNTB would be 4 . Compared to PD-1 negative patients, the number of response cases added per 1000 individuals by PD-1 positive patients was 243. Subgroup analysis identified that PD-L1 positive patients had a significantly increased response rate during the treatment of all three anti-PD-1/PD-L1 antibodies Nivolumab $(\mathrm{RR}=1.70,95 \%$ CI: 1.32-2.17, $P<0.001)$, Pembrolizumab $(\mathrm{RR}=2.56,95 \% \mathrm{CI}: 1.23-5.35, P<0.001)$ and MPDL3280A $(\mathrm{RR}=2.40,95 \% \mathrm{CI}: 1.48-3.88$, $P=0.001$ ) (Table 2 and Supplementary Figure S3B). Subgroup analysis also identified that PD-L1 positive 
melanoma $(\mathrm{RR}=1.42,95 \% \mathrm{CI}: 1.22-1.65, P<0.001)$, NSCLC (RR $=2.61,95 \% \mathrm{CI}: 1.87-3.65, P<0.001)$ and RCC patients $(\mathrm{RR}=1.91,95 \% \mathrm{CI}: 1.06-3.44, P=0.032)$ had a significant increase in the response rates (Table 3 and Supplementary Figure S3C). Smoker patients also showed a significantly higher response rate than non-smoker patients (2 studies, $\mathrm{RR}=5.45,95 \% \mathrm{CI}$ : $1.13-26.18$, $P=0.034)$ without heterogeneity $\left(I^{2}=0.00 \%, \chi^{2}=0.22\right.$, $P=0.638$ ) (Table 3 and Supplementary Figure S4A). However, there was no significant difference between BRAF mutation and previous Ipilimumab treatment history (Table 3, Supplementary Figure S4B and S4C).
Due to the limited number of available publications, other factors weren't included in this meta-analysis.

\section{Overall adverse effect rates}

The overall pooled adverse effect rate of anti-PD-1/ PD-L1 antibodies was 16\% (95\% CI: 12\%-21\%), (Table 1 and Supplementary Figure S5A). Egger's regression asymmetry test $(P=0.922)$ showed no evidence of substantial publication bias. Subgroup analyses also pooled the adverse effect rates for each drug and tumor (Table 1, Supplementary Figure S5B and S5C). The pooled

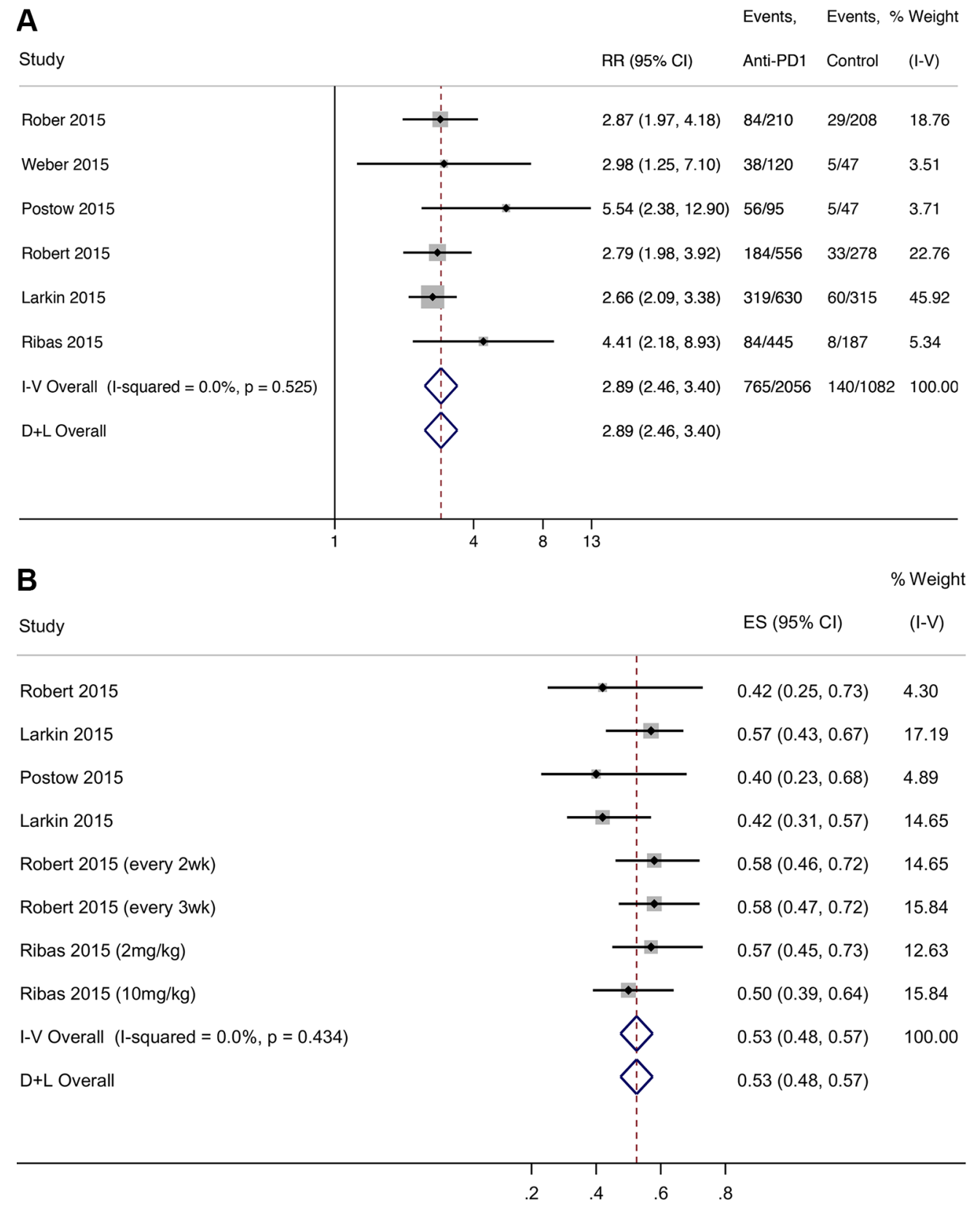

Figure 2: Forest plot for ratio risk and confidence intervals of response rate (A) and PFS survival (B) of anti-PD-1 antibody compared with other therapies for melanoma. 
Table 2: Potential biomarkers for predicting clinical outcomes of PD-1/PD-L1 antibody application

\begin{tabular}{|c|c|c|c|c|c|}
\hline & Melanoma & NSCLC & RCC & $\begin{array}{l}\text { Hematologic } \\
\text { malignancies }\end{array}$ & $\begin{array}{l}\text { Others solid tumor } \\
\text { (Colon, bladder, etc) }\end{array}$ \\
\hline 1. PD1/PD-L1 signaling pathway & $\begin{array}{l}\text { PD-L1 expression on } \\
\text { tumor cells }(9)\end{array}$ & $\begin{array}{l}\text { PD-L1 expression on tumor } \\
\text { cells }(6) \text { and TIL(1) }\end{array}$ & $\begin{array}{l}\text { PD-L1 expression } \\
\text { on tumor cells ( } 2 \text { ) }\end{array}$ & $\begin{array}{l}\text { PD-L1, PD-L2 copy } \\
\text { number (1) and PD-L1 } \\
\text { expression(1) }\end{array}$ & $\begin{array}{l}\text { PD-L1 expression on tumor } \\
\text { cells ( } 2 \text { ) and TIL (1) }\end{array}$ \\
\hline 2. Genes mutation & BRAF (3) & $\operatorname{EGFR(2),~KRAS(2)~}$ & NA & NA & Mismatch repair status (1) \\
\hline 3. Lymphocytes subgroup & $\begin{array}{l}\mathrm{CD} 25^{+} \text {Treg/CD4 } \\
\text { ratio(1), MDSC }(1), \mathrm{CD} 8 \mathrm{~T} \\
\text { cell }(1), \mathrm{T}_{\text {regs }}\left(\mathrm{CD} 4^{+} \mathrm{CD} 25^{+}\right. \\
\left.\mathrm{CD} 127^{\text {low FoxP3 }}{ }^{+}\right) \quad(1), \\
\text { Absolute lymphocyte } \\
\text { Count (1) }\end{array}$ & $\begin{array}{l}\mathrm{CD} 8^{+} \mathrm{HLA}-\mathrm{DR}^{+} \mathrm{Ki}-67^{+} \mathrm{T} \text { cells } \\
\text { (1) }\end{array}$ & NA & $\begin{array}{l}\mathrm{CD} 4^{+} \mathrm{T} \text { cell }(1), \mathrm{T}_{\mathrm{FH}} \\
\left(\mathrm{PD} 1^{\text {hi }} \mathrm{CXCR} 5^{\mathrm{hi}}\right), \mathrm{T}_{\text {eff }} \\
\left(\mathrm{PD} 1^{\text {int }} \mathrm{CXCR} 5^{\text {int }} \text { or }\right. \\
\left.\mathrm{PD} 1^{\mathrm{lo}} \mathrm{CXCR} 5^{\text {lo }}\right)(1)\end{array}$ & CD8 T cell (1) \\
\hline 4. Blood immune biomarkers & NA & IL-18, ITAC, IFN- $\gamma$, IL-6 (1) & NA & NA & NA \\
\hline 5. Others & NA & Smoke history(3) & NA & FLIPIP1, FLIPI2(1) & NA \\
\hline
\end{tabular}

Note: $\mathrm{TIL}=$ tumor infiltrating lymophocyte; $\mathrm{T}_{\mathrm{regs}}=$ regulatory $\mathrm{T}$ cell; $\mathrm{T}_{\mathrm{FH}}=$ follicular helper $\mathrm{T}$ cell, $\mathrm{T}_{\text {eff }}=$ effector $\mathrm{T}$ cell, FLIPI $=$ Follicular lymphoma international prognostic index; $(n)=$ number of trials tested the biomarkers.

Table 3: Meta-analysis of clinical responses based on PD-L1 expression, smoke history, BRAF and Ipilimumab treatment history

\begin{tabular}{|c|c|c|c|c|c|c|}
\hline & & \multicolumn{2}{|c|}{ Sample size } & RR $(95 \%$ CI $)$ & $P$ value & Study $(n)$ \\
\hline \multicolumn{2}{|c|}{ PD-L1 expression } & Positive & Negative & & & \\
\hline & Total & $\begin{array}{l}356 / 859 \\
(41.4 \%)\end{array}$ & $\begin{array}{c}411 / 1549 \\
(26.5 \%)\end{array}$ & $1.92(1.52,2.41)$ & $<0.001$ & 20 \\
\hline \multirow{3}{*}{$\begin{array}{l}\text { Subgroup } \\
\text { (drug) }\end{array}$} & Nivolumab & $\begin{array}{l}231 / 547 \\
(42.2 \%)\end{array}$ & $\begin{array}{c}317 / 1034 \\
(29.7 \%)\end{array}$ & $1.69(1.32,2.17)$ & $<0.001$ & 14 \\
\hline & Pembrolizumab & $\begin{array}{c}87 / 187 \\
(46.5 \%)\end{array}$ & $\begin{array}{c}73 / 362 \\
(20.2 \%)\end{array}$ & $2.56(1.23,5.35)$ & 0.012 & 3 \\
\hline & MPDL3280A & $\begin{array}{c}38 / 125 \\
(30.4 \%) \\
\end{array}$ & $\begin{array}{c}21 / 153 \\
(13.7 \%) \\
\end{array}$ & $2.39(1.48,3.88)$ & $<0.001$ & 3 \\
\hline \multirow{6}{*}{$\begin{array}{l}\text { Subgroup } \\
\text { (tumor type) }\end{array}$} & Melanoma & $\begin{array}{l}190 / 340 \\
(55.9 \%)\end{array}$ & $\begin{array}{l}309 / 732 \\
(42.2 \%)\end{array}$ & $1.42(1.22,1.65)$ & $<0.001$ & 6 \\
\hline & NSCLC & $\begin{array}{l}100 / 306 \\
(32.7 \%)\end{array}$ & $\begin{array}{c}63 / 510 \\
(12.4 \%)\end{array}$ & $2.61(1.87,3.65)$ & $<0.001$ & 5 \\
\hline & $\mathrm{RCC}$ & $\begin{array}{c}19 / 86 \\
(22.1 \%)\end{array}$ & $\begin{array}{c}19 / 140 \\
(13.6 \%)\end{array}$ & $1.91(1.06,3.44)$ & 0.032 & 3 \\
\hline & Ovarian cancer & $\begin{array}{c}2 / 16 \\
(12.5 \%)\end{array}$ & $\begin{array}{c}1 / 4 \\
(25.0 \%)\end{array}$ & $0 \cdot 50(0.06,4.23)$ & 0.525 & 1 \\
\hline & Bladder cancer & $\begin{array}{c}13 / 30 \\
(43.35 \%)\end{array}$ & $\begin{array}{c}4 / 35 \\
(11.4 \%)\end{array}$ & $3.79(1.38,10.40)$ & 0.010 & 1 \\
\hline & Mixed cancer* & $\begin{array}{c}32 / 87 \\
(36.8 \%)\end{array}$ & $\begin{array}{c}15 / 128 \\
(11.7 \%)\end{array}$ & $4.61(1.35,15.74)$ & 0.015 & 4 \\
\hline \multicolumn{2}{|c|}{ Smoke history (NSCLC) } & Smoked & No-smoked & & & \\
\hline & Total & $\begin{array}{c}31 / 92 \\
(33.7 \%)\end{array}$ & $\begin{array}{c}1 / 24 \\
(4.2 \%)\end{array}$ & $6.02(1.22,29.75)$ & 0.028 & 2 \\
\hline \multicolumn{2}{|c|}{ BRAF (Melanoma) } & Wild & Mutation & & & \\
\hline & Total & $\begin{array}{l}113 / 297 \\
(38.0 \%)\end{array}$ & $\begin{array}{c}23 / 75 \\
(30.7 \%)\end{array}$ & $1.32(0.92,1.89)$ & 0.128 & 3 \\
\hline \multicolumn{2}{|c|}{ Ipilimumab treatment (Melanoma) } & Naive & Treated & & & \\
\hline & Total & $\begin{array}{c}34 / 114 \\
(29.8 \%)\end{array}$ & $\begin{array}{c}26 / 93 \\
(28.0 \%)\end{array}$ & $1.01(0.64,1.59)$ & 0.969 & 2 \\
\hline
\end{tabular}

Note: *Mix cancer: multiple tumors included in these four studies but can't be separately totally by tumor types. 
adverse effect rates for Nivolumab and Pembrolizumab were $18 \%(95 \% \mathrm{CI}: 11 \%-26 \%, \mathrm{Z}=7.70, P<0.001)$ and 9\% (95\% CI: 6\%-14\%, Z = 7.43, $P<0.001)$, respectively. Anti-PD-1/PD-L1 antibodies combined with other therapies had a higher adverse effect rate of $29 \%(95 \%$ CI: $14 \%-46 \%, \mathrm{Z}=5.64, P<0.001)$ than that of $13 \%$ with anti-PD-1/PD-L1 antibodies alone (95\% CI: 10\%-16\%, $\mathrm{Z}=14.98, P<0.001$ ) (Supplementary Figure S5D).

\section{Anti-PD-1 antibody showed higher safety compared with regular chemotherapy and Ipilimumab}

We also compared the adverse effect rates of Nivolumab and Pembrolizumab with other therapies including chemotherapy and anti-CTLA4 antibody (clinical data showed in Supplementary Table S1). Metaanalysis showed that the anti-PD-1 antibody was associated with a significant decrease in adverse effect rate compared with other therapies $(\mathrm{RR}=0.49,95 \% \mathrm{CI}: 0.30-0.80$, $P=0.004)$, with large heterogeneity $\left(I^{2}=95.3, \chi^{2}=171.02\right.$, $P<0.001)$ (Figure 3). Egger's regression asymmetry test $(P=0.415)$ and Begg's test $(P=0.754)$ showed no evidence of substantial publication bias. Compared to 376 out of 1000 patients having adverse events in the group with other therapies, only 184 out of 1000 had adverse events with the anti-PD-1 antibody. Based on a rate of $37.6 \%$ in the group with other therapies, the NNTB would be 5 . Compared to the group with other therapies, the number of adverse cases was reduced by 192 per 1000 individuals with the PD-1 antibody. Meta-regression analysis showed that Nivolumab/Ipilimumab combination was significantly positively associated with adverse effect rate $(P=0.022$, Supplementary Table S3). Subgroup analysis also showed that Nivolumab/Ipilimumab combination increased adverse effects $(\mathrm{RR}=1.45,95 \%$ CI: 0.65-3.24), but did not reach statistical significance.

\section{DISCUSSION}

In this study, meta-analysis of existing clinical studies demonstrated the high efficacy and safety of antiPD-1/PD-L1 antibodies for various cancers, especially melanoma, NSCLC and RCC. The overall response rates of anti-PD-1/PD-L1 antibodies for advanced melanoma patients was $29 \%$, which was higher than the 5-20\% response rates from well-tolerated chemotherapies [23]. Ipilimumab, the first immune check point inhibitor targeted CTLA4, showed an objective response only $11 \%$ $[24,25]$. We compared Nivolumab and Pembrolizumab with regular chemotherapy (including Ipilimumab) in melanoma patients. Nivolumab and Pembrolizumab showed higher response rate and reduced risk of death. The overall response rates of anti-PD-1/PD-L1 antibodies for NSCLC and RCC were both $21 \%$. However, we didn't compare the anti-PD-1/PD-L1 antibodies with other therapies in NSCLC and RCC because there were only two studies that compared Nivolumab with Docetaxel

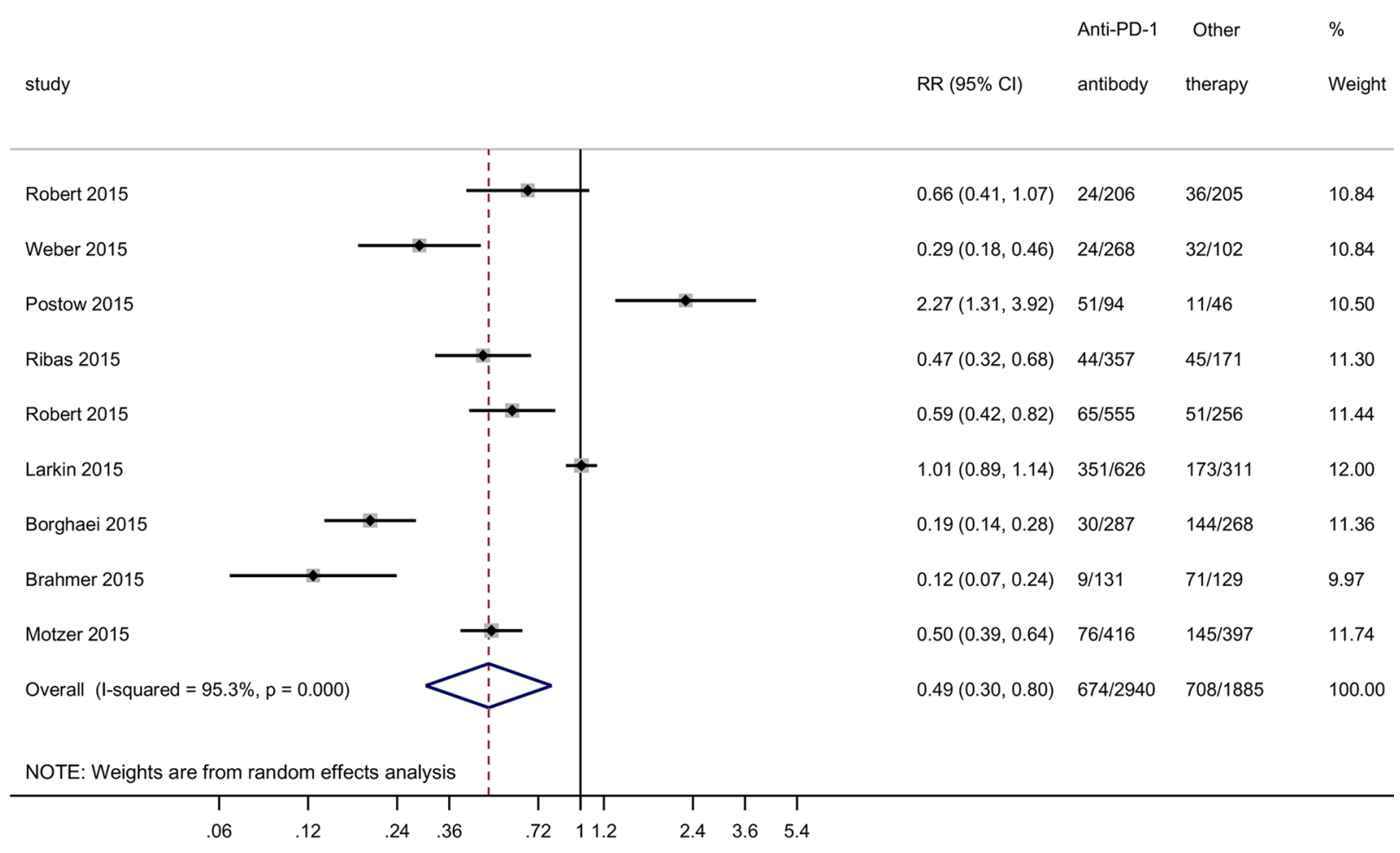

Figure 3: Forest plot for ratio risk and confidence intervals of adverse effect rate of anti-PD-1 antibody treatment compared with other therapies. 
in advanced NSCLC [26, 27] and only one study that compared Nivolumab with Everolimus in advanced RCC [28]. But in these trials, Nivolumab was reported with improved overall survival and response rates, as well as reduced adverse effect rates compared with regular chemotherapy. For other solid tumors, the response rates were limited due to the limited publications.

Our results showed a higher response rate in hematologic malignancy patients than solid tumor patients. Hematologic malignancies patients may more easily benefit from immunotherapy compared with solid tumors because of the insufficient $\mathrm{T}$ cell infiltration and highly immunosuppressive microenvironment in solid tumors [29]. In addition, some hematologic malignancies patients received anti-PD-1 antibody treatment after autologous stem-cell transplantation. This previous treatment might improve the immunological responses of anti-PD-1 antibody by restoring the body's ability to make normal blood cells.

PD-L1 expression might serve as a biomarker for anti-PD-1/PD-L1 antibody response. In our metaanalysis of pooled outcome from 20 trials, anti-PD-1/ PD-L1 antibodies had the higher response rates in PD-L1 positive patients than that in PD-L1 negative patients. PDL1 positive seems to predict the response for melanoma, NSCLC, RCC and bladder cancer patients. Concerning drugs, PD-L1 positive seems to predict the response for Nivolumab, Pembrolizumab and MPDL3280A. A similar result was reported by another group [30]. All of the PD-L1 expression results came from IHC staining. In most studies, IHC staining of more than 5\% was defined as PD-L1 positive, but $10 \%$ and $1 \%$ were also used as the cut-off criterion in some studies. IHC staining platform, antibodies used and result evaluation method all contributed to the result heterogeneity. T1PD-L1 expression can be activated by monogenic signaling pathway PTEN loss, JAK/STAT, EGFR or cytokines released by immunologic response [32]. Since the PD-L1 expression is dynamic, the statuses of the tumor samples for detection, before, during or after previous treatment or immunotherapies also affected the PD-L1 IHC results $[32,33]$. The distinct methods and interpretation in PDL1 IHC assessment challenged the clinical application of PD-L1 expression as the biomarker for PD-1/PD-L1 antibodies.

Genetic mutation was an important factor associated with the responses of anti-PD-1/PD-L1 antibodies [34, 35]. Higher nonsynonymous mutation burden in tumors was associated with improved objective response, durable clinical benefit, and progression-free survival after antiPD-1/PD-L1 antibody therapy. For instance, mismatchrepair status (DNA repair and replication gene mutations such as POLD1, POLE and MSH2) could predict clinical benefit of Pembrolizumab for colon cancer patients and the high somatic mutation burden was associated with prolonged PFS survival [16]. In NSCLC, KRAS mutation positive patients had better overall survival from Nivolumab than docetaxel [29]. In Gettinger's study, responses were seen in patients with EGFR/KRAS wild type and EGFR/ KRAS mutant received Nivolumab [11].

Genetic mutation and epigenetic modification could alter the expression of tumor associated selfantigens, induce more neoantigens and enhance tumor antigenicities, thereby increasing the anti-tumor immune responses in tumor microenvironments [36]. Neoantigen was identified as the tumor-specific antigen arisen as a consequence of tumor-specific mutations. Recent research showed that recognition of patient-specific neoantigens is a major factor in the activity of clinical anti-PD-1/PD-L1 immunotherapy [36]. It's possible that the burden of candidate neoantigens correlated with antiPD-1/PD-L1 antibody response, but not the frequency per nonsynonymous mutation. $\mathrm{s}$ with presenting in approximately $40 \%$ of melanoma patients 37 , 80urm Areported a similar result: after ing9This may be due to the limited population, but could also be because a single BRAF V600 mutation is not enough to work as the biomarker for anti-PD-1/PD-L1 antibodies.

Meanwhile, ometa-analysis a higher response rate inSve4 Therefore smoker patients may have a higher burden of candidate neoantigens, which was correlated with higher response rate for PD-1/PD-L1 antibodies. eda These results suggested that perhaps a systematic evaluation on tumor neoantigen landscape but not a single specific factor should be employed to predict the response for anti-PD-1/PD-L1 antibody.

Immune checkpoint inhibitors have also been linked to the development of certain adverse events. The comment treatment related adverse effects have rash, diarrhea, fatigue, neutropenia, decreased platelet count, thrombocytopenia, hypothyroidism and others [8-11]. The overall adverse effect rate pooled in our meta-analysis results was $16 \%$. Anti-PD-1/PD-L1 antibodies are well tolerated in patients. Similar adverse effects were reported in Pembrolizumab and Nivolumab [8, 40, 41]. The safety profiles of different anti-PD-1/PD-L1 antibodies or tumors are similar except for Pidilizumab in the treatment of hematologic malignancies. This might be because most patients recruited in these two Pidilizumab trials were patients with hematologic malignancies. The subgroup analysis showed higher adverse effect rate in patients with hematologic malignancies (30\%) compared with solid tumors (9-26\%). Even so, the adverse effect rate of anti-PD-1/PD-L1 antibodies for patients with hematologic malignancies was still lower than that of other regular therapies, even in contrast to anti-CTL4 antibody. Moreover, our result showed Nivolumab and Pembrolizumab could reduce adverse effects compared with other therapies. Concerning the control type, our data analysis didn't show a lower adverse effect rate of Nivolumab and Pembrolizumab when compare with Ipilimumab. This may be due to the limited trial included 
in the meta-analysis. Interestingly, our results found that combination with other therapies has the potential to increase the adverse effect rate as well as to increase the response rate. Blocking of $\mathrm{PD}-1$ alone might not fully restore the function of antitumor $\mathrm{T}$ cells because of other inhibitory receptors such as CTL-4, LAG3, TIM3, BTLA, CD160, and CD244 [5, 14, 42]. Our findings suggest the necessity of to balancing the clinical outcome with the adverse effects when using combination strategies of antiPD-1/PD-L1 antibodies for advanced cancer patients.

Our review also has limitations. Firstly, high heterogeneity was found when we pooled the overall response rate and adverse effect rate. Because of participated heterogenerity, we used random-effects model to pool studies and performed subgroup analysis and meta-regression analysis. NSCLC, combination therapy and antigen origin positively associated with antiPD-1/PD-L1 antibody responses. The heterogeneity was reduced in NSCLC and anti-PD-L1 antibody and some other subgroups, but high heterogeneity was still found in most part of subgroups. Since no evidence of substantial publication bias was found, these results suggested the necessity of valuable biomarkers to evaluate clinical outcomes of anti-PD1/PD-L1 antibodies. Secondly, few trials were collected for some outcomes such as comparing the response rate and adverse effects rate between antiPD-1/PD-L1 antibodies with other therapy, and comparing response rate between smoke history, BRAF mutation status, and previous Ipilimumab treatment. More research is needed to understand and evaluate these clinical outcomes.

In conclusion, our meta-analysis with existing clinical studies verified the high efficacy and safety of antiPD-1/PD-L1 antibodies in melanoma, NSCLC, RCC and other cancers. More importantly, the results of this metaanalysis supported the notion that PD-L1 expression and smoke history are correlated with better clinical responses of anti-PD-1/PD-L1 antibodies. Our study is the most upto-date updated meta-analysis to present an evaluation for efficacy and safety of anti-PD-1/PD-L1 antibodies for the treatment of advanced or refractory cancer patients, which supports future clinical applications for anti-PD-1/PD-L1 antibody-based immunotherapy.

\section{MATERIALS AND METHODS}

\section{Data sources and searches}

The deadline for trial publication and/or presentation was January 31th, 2016. Systematic literature searches were conducted in PubMed and EMBASE according to Cochrane guidelines [43]. Search key terms included PD-1, PD-L1, Nivolumab, Pembrolizumab, Lambrolizumab, MPDL3280A, BMS-936559, cancer, tumor, carcinoma, phase I, phase II, phase III. We also manually searched references in identified studies in case of missing trials.

\section{Study selection}

The eligible studies were limited to human clinical trials published in English. Studies were included if they performed clinical trials with anti-PD-1/PD-L1 antibodies for advanced or refractory cancer patients, reporting either the efficiency or safety. Meeting abstracts in the EMBA database from ASCO (www.asco.org) and ESMO (www.esmo.org) published in the last two years were also included. When part or all of the patients were involved in more than one publication, only the most complete or most informative study was included in this analysis.

\section{Data extraction and quality assessment}

All the eligible papers were reviewed and extracted independently by two investigators, and the disagreements were resolved by discussion; a third investigator adjudicated the controversial parts. For each included study, data set was extracted from each article by patients' tumor type. Extracted data included followings: adopted drugs, tumor types, sample size, patients' previous treatment status, combination strategies, control setup, patients' response, PFS, median PFS data, Hazard ratios (HRs), Grade 3 and 4 adverse effects, and potential biomarkers to predict which patients might benefit from anti-PD-1/PD-L1 antibodies if assessed in the manuscript.

The primary endpoint was patients' response to anti-PD-1/PD-L1 antibodies. The responses were derived from independent, central, blinded radiologic review, with assessment according to the Response Evaluation Criteria in Solid Tumors (RECIST) [44]. Patients with responses to anti-PD-1/PD-L1 antibody immunotherapy were divided into two groups: positive response group [patients achieved complete response (CR, all target lesions disappearance) or partial response (PR, at least a $30 \%$ decrease in the sum of the longest diameter of target lesions)], and negative response group [patients achieved stable disease (SD, neither sufficient shrinkage to qualify for PR nor sufficient increase to qualify for PD), progress disease (PD, at least a $20 \%$ increase in the sum of the longest diameter of target lesions)]. The overall response rates were the percentage of patients that achieved complete response and partial response. The second endpoint included the safety and survival. Grade 3 and 4 adverse effects were graded according to the National Cancer Institute Common Toxicity Criteria. Survival was indicated by progression-free survival (PFS).

In order to ensure the quality of the meta-analysis, two authors independently evaluated the quality of the studies included in the systematic review using the Methodological Index for Nonrandomized Studies (MINORS) [45]. The MINORS scale included 8 criteria for nonrandomized studies and additional 4 criteria in the case of comparative studies. 


\section{Data synthesis and analysis}

For clinical response and adverse effect rate, the overall rate was pooled by Metaprop in Stata. Metaprop is a statistical program implemented to perform metaanalyses of proportions as mentioned in our former study $[46,47]$. It provides appropriate methods for dealing with proportions close to $0 \%$ or $100 \%$. Cochran's $Q$ test was used to assess between-study differences and the $\mathrm{I}^{2}$ statistic to quantify the proportion of observed inconsistency across study results not explained by chance. If the heterogeneity among trials was very large ( $I^{2}$ statistic $>75 \%$ ), a random effects meta-analysis was used. The pooled response rates or adverse effect rates describe the mean of the distribution of the estimated response rates. To compare response rates and adverse effect rates of antiPD-1/PD-L1 antibodies with other therapy regimens and the response rates between different biomarker statuses, the relative ratio (RR) was calculated. To analyze the PFS, the hazard ratios (HRs) and their CIs were estimated using the methods proposed by Parmer [48]. When there was an effect, a number needed to treat for an additional beneficial outcome (NNTB) or number needed to treat for an additional harmful outcome (NNTH) was calculated from the RR.

To explore the sources of heterogeneity, metaregression analyses were conducted by pre-defined subgroups including adopted drugs, tumor types, combination strategies and antigen origin. We also compared pooled results obtained from subsets of studies grouped according to the tumor type, drugs used and combination strategies. Univariate meta-regression analyses were conducted to identify clinical factors associated with adverse effects. Next, we performed a multivariable meta-regression analysis including the significant factors in the univariate analysis. Potential interaction was also tested between potential predictors. Publication bias was analyzed by both Begg's and Egger's regression asymmetry test, and visually evaluated using the funnel plot. Stata Statistical Software (version 13.0 Stata Corp., College Station, TX, USA) was used for all analyses. A two-sided $P$ value $\leq 0.05$ was considered as statistically significant.

\section{ACKNOWLEDGMENTS}

We thank Melissa La Bianca Middleton from La Bianca Learning Center of Boston for English editing and Xin Yuan from Beth Israel Deaconess Medical Center, Harvard Medical School for advising.

\section{CONFLICTS OF INTEREST}

The authors have declared that no conflicts of interest exits.

\section{GRANT SUPPORT}

This work was funded by National Natural Science Foundation of China (Grant numbers 812111102, 81171986, 81271815 and 31400752), Research Grant from the Ministry of Public Health (Grant number 201501004), Funds for Creative Research Team of Henan Province, Creative Research Team of Higher Education of Henan Province.

\section{REFERENCES}

1. Siegel RL, Miller KD, Jemal A. Cancer statistics 2015. CA Cancer J Clin. 2015; 65:5-29.

2. Urruticoechea A, Alemany R, Balart J, Villanueva A, Viñals F, Capellá G. Recent advances in cancer therapy: an overview. Curr Pharm Des. 2010; 16:3-10.

3. Hanahan D, Weinberg RA. Hallmarks of cancer: the next generation. Cell. 2011; 144:646-74.

4. Mellman I, Coukos G, Dranoff G. Cancer immunotherapy comes of age. Nature. 2011; 480:480-9.

5. Pardoll DM. The blockade of immune checkpoints in cancer immunotherapy. Nat Rev Cancer. 2012; 12:252-64.

6. Nishimura $H$, Nose $M$, Hiai $H$, Minato $N$, Honjo $T$. Development of lupus-like autoimmune diseases by disruption of the PD-1 gene encoding an ITIM motifcarrying immunoreceptor. Immunity. 1999; 11:141-51.

7. Dong H, Strome SE, Salomao DR, Tamura H, Hirano F, Flies DB, Roche PC, Lu J, Zhu G, Tamada K, Lennon VA, Celis E, Chen L. Tumor-associated B7-H1 promotes T-cell apoptosis: a potential mechanism of immune evasion. Nat Med. 2002; 8:793-800.

8. Robert C, Ribas A, Wolchok JD, Hodi FS, Hamid O, Kefford R, et al. Anti-programmed-death-receptor-1 treatment with pembrolizumab in ipilimumab-refractory advanced melanoma: a randomised dose-comparison cohort of a phase 1 trial. Lancet 2014; 384:1109-17.

9. Weber JS, D'Angelo SP, Minor D, Hodi FS, Gutzmer R, Neyns B, Hoeller C, Khushalani NI, Miller WH Jr, Lao CD, Linette GP, Thomas L, Lorigan P, et al. Nivolumab versus chemotherapy in patients with advanced melanoma who progressed after anti-CTLA-4 treatment (CheckMate 037): a randomised, controlled, open-label, phase 3 trial. Lancet Oncol. 2015; 16:375-84.

10. Garon EB, Rizvi NA, Hui R, Leighl N, Balmanoukian AS, Eder JP, Patnaik A, Aggarwal C, Gubens M, Horn L, Carcereny E, Ahn MJ, Felip E, et al. Pembrolizumab for the treatment of non-small-cell lung cancer. N Engl J Med. $2015 ; 372: 2018-28$.

11. Gettinger SN, Horn L, Gandhi L, Spigel DR, Antonia SJ, Rizvi NA, Powderly JD, Heist RS, Carvajal RD, Jackman DM, Sequist LV, Smith DC, Leming P, et al. Overall Survival and Long-Term Safety of Nivolumab 
(Anti-Programmed Death 1 Antibody, BMS-936558, ONO4538) in Patients With Previously Treated Advanced NonSmall-Cell Lung Cancer. J Clin Oncol. 2015; 33:2004-12.

12. Berger R, Rotem-Yehudar R, Slama G, Landes S, Kneller A, Leiba M, Koren-Michowitz M, Shimoni A, Nagler A. Phase I safety and pharmacokinetic study of CT-011, a humanized antibody interacting with PD-1, in patients with advanced hematologic malignancies. Clin Cancer Res. 2008; 14:3044-51.

13. Armand P, Nagler A, Weller EA, Devine SM, Avigan DE, Chen YB, Kaminski MS, Holland HK, Winter JN, Mason JR, Fay JW, Rizzieri DA, Hosing CM, et al. Disabling immune tolerance by programmed death-1 blockade with pidilizumab after autologous hematopoietic stem-cell transplantation for diffuse large B-cell lymphoma: results of an international phase II trial. J Clin Oncol. 2013; 31:4199-206.

14. Westin JR, Chu F, Zhang M, Fayad LE, Kwak LW, Fowler N, Romaguera J, Hagemeister F, Fanale M, Samaniego F, Feng L, Baladandayuthapani V, Wang Z, et al. Safety and activity of PD-1 blockade by pidilizumab in combination with rituximab in patients with relapsed follicular lymphoma: a single group, open-label, phase 2 trial. Lancet Oncol. 2014; 15:69-77.

15. Ansell SM, Lesokhin AM, Borrello I, Halwani A, Scott EC, Gutierrez M, Schuster SJ, Millenson MM, Cattry D, Freeman GJ, Rodig SJ, Chapuy B, Ligon AH, et al. PD-1 blockade with nivolumab in relapsed or refractory Hodgkin's lymphoma. N Engl J Med. 2015; 372:311-9.

16. Le DT, Uram JN, Wang H, Bartlett BR, Kemberling H, Eyring AD, Skora AD, Luber BS, Azad NS, Laheru D, Biedrzycki B, Donehower RC, Zaheer A, et al. PD-1 Blockade in Tumors with Mismatch-Repair Deficiency. N Engl J Med. 2015; 372:2509-20.

17. Motzer RJ, Rini BI, McDermott DF, Redman BG, Kuzel TM, Harrison MR, Vaishampayan UN, Drabkin HA, George S, Logan TF, Margolin KA, Plimack ER, Lambert AM, et al. Nivolumab for Metastatic Renal Cell Carcinoma: Results of a Randomized Phase II Trial. J Clin Oncol. 2014; 33:1430-7

18. McDermott DF, Drake CG, Sznol M, Choueiri TK, Powderly JD, Smith DC, Brahmer JR, Carvajal RD, Hammers HJ, Puzanov I, Hodi FS, Kluger HM, Topalian SL, et al. Survival, durable response, and longterm safety in patients with previously treated advanced renal cell carcinoma receiving nivolumab. J Clin Oncol. 2015; 33:2013-20.

19. Powles T, Eder JP, Fine GD, Braiteh FS, Loriot Y, Cruz C, Bellmunt J, Burris HA, Petrylak DP, Teng SL, Shen X, Boyd Z, Hegde PS, et al. MPDL3280A (anti-PD-L1) treatment leads to clinical activity in metastatic bladder cancer. Nature. 2014; 515:558-62.

20. Hamanishi J, Mandai M, Ikeda T, Minami M, Kawaguchi A, Murayama T, Kanai M, Mori Y, Matsumoto S, Chikuma S, Matsumura N, Abiko K, Baba T, et al. Safety and Antitumor
Activity of Anti-PD-1 Antibody, Nivolumab, in Patients With Platinum-Resistant Ovarian Cancer. J Clin Oncol. 2015; 33:4015-22.

21. Jia M, Feng W, Kang S, Zhang Y, Shen J, He J, Jiang L, Wang W, Guo Z, Peng G, Chen G, He J, Liang W. Evaluation of the efficacy and safety of anti-PD-1 and anti-PD-L1 antibody in the treatment of non-small cell lung cancer (NSCLC): a meta-analysis. J Thorac Dis. 2015;7:455-61.

22. Yang Y, Pang Z, Ding N, Dong W, Ma W, Li Y, Du J, Liu Q. The efficacy and potential predictive factors of PD-1/PD-L1 blockades in epithelial carcinoma patients: a systematic review and meta analysis. Oncotarget. 2016; 7:7435074361. doi: 10.18632/oncotarget.11291.

23. Bhatia S, Tykodi SS, Thompson JA. Treatment of metastatic melanoma: an overview. Oncology (Williston Park). 2009; 23:488-96.

24. Robert C, Thomas L, Bondarenko I, O'Day S, Weber J, Garbe C, Lebbe C, Baurain JF, Testori A, Grob JJ, Davidson N, Richards J, Maio M, et al. Ipilimumab plus dacarbazine for previously untreated metastatic melanoma. N Engl J Med. 2011; 364:2517-26.

25. Danielli R, Ridolfi R, Chiarion-Sileni V, Queirolo P, Testori A, Plummer R, Boitano M, Calabrò L, Rossi CD, Giacomo AM, Ferrucci PF, Ridolfi L, Altomonte M, et al. Ipilimumab in pretreated patients with metastatic uveal melanoma: safety and clinical efficacy. Cancer Immunol Immunother. 2012; 61:41-8.

26. Al-Farsi A, Ellis PM. Treatment paradigms for patients with metastatic non-small cell lung cancer, squamous lung cancer: first, second, and third-line. Front Oncol. 2014; 4:157.

27. Levy A, Menard J, Albiges L, Loriot Y, Di Palma M, Fizazi K, Escudier B. Second line treatment of metastatic renal cell carcinoma: The Institut Gustave Roussy experience with targeted therapies in 251 consecutive patients. Eur J Cancer. 2013; 49:1898-904.

28. Brahmer J, Reckamp KL, Baas P, Crinò L, Eberhardt WE, Poddubskaya E, Antonia S, Pluzanski A, Vokes EE, Holgado E, Waterhouse D, Ready N, Gainor J, et al. Nivolumab versus Docetaxel in Advanced SquamousCell Non-Small-Cell Lung Cancer. N Engl J Med. 2015; 373:123-35.

29. Borghaei H, Paz-Ares L, Horn L, Spigel DR, Steins M, Ready NE, Chow LQ, Vokes EE, Felip E, Holgado E, Barlesi F, Kohlhäufl M, Arrieta $\mathrm{O}$, et al. Nivolumab versus Docetaxel in Advanced Nonsquamous Non-Small-Cell Lung Cancer. N Engl J Med. 2015; 373:1627-39.

30. Carbognin L, Pilotto S, Milella M, Vaccaro V, Brunelli M, Caliò A, Cuppone F, Sperduti I, Giannarelli D, Chilosi M, Bronte V, Scarpa A, Bria E, et al. Differential Activity of Nivolumab, Pembrolizumab and MPDL3280A according to the Tumor Expression of Programmed Death-Ligand-1 (PD-L1): Sensitivity Analysis of Trials in Melanoma, Lung and Genitourinary Cancers. PLoS On. 2015;10:e0130142. 
31. Motzer RJ, Escudier B, McDermott DF, George S, Hammers HJ, Srinivas S, Tykodi SS, Sosman JA, Procopio G, Plimack ER, Castellano D, Choueiri TK, Gurney H, et al. Nivolumab versus Everolimus in Advanced Renal-Cell Carcinoma. N Engl J Med. 2015; 373:1803-13.

32. Chae YK, Pan A, Davis AA, Raparia K, Mohindra NA, Matsangou M, Giles FJ. Biomarkers for PD-1/PD-L1 Blockade Therapy in Non-Small-cell Lung Cancer: Is PDL1 Expression a Good Marker for Patient Selection? Clin Lung Cancer. 2016. [Epub ahead of print]

33. Villaruz LC, Socinski MA. The clinical utility of PD-L1 testing in selecting non-small cell lung cancer patients for PD1/PD-L1-directed therapy. Clin Pharmacol Ther. 2016;100:212-4.

34. Rizvi NA, Hellmann MD, Snyder A, Kvistborg P, Makarov V, Havel JJ, Lee W, Yuan J, Wong P, Ho TS, Miller ML, Rekhtman N, Moreira AL, et al. Cancer immunology. Mutational landscape determines sensitivity to PD-1 blockade in non-small cell lung cancer. Science. 2015; 348:124-8.

35. Snyder A, Makarov V, Merghoub T, Yuan J, Zaretsky JM, Desrichard A, Walsh LA, Postow MA, Wong P, Ho TS, Hollmann TJ, Bruggeman C, Kannan K, et al. Genetic basis for clinical response to CTLA-4 blockade in melanoma. N Engl J Med. 2014;371:2189-99.

36. Schumacher TN, Schreiber RD. Neoantigens in cancer immunotherapy. Science. 2015; 348:69-74.

37. Lawrence MS, Stojanov P, Polak P, Kryukov GV, Cibulskis K, Sivachenko A, Carter SL, Stewart C, Mermel CH, Roberts SA, Kiezun A, Hammerman PS, McKenna A, et al. Mutational heterogeneity in cancer and the search for new cancer-associated genes. Nature. 2013; 499:214-8.

38. Larkin J, Ascierto PA, Dréno B, Atkinson V, Liszkay G, Maio M, Mandalà M, Demidov L, Stroyakovskiy D, Thomas L, de la Cruz-Merino L, Dutriaux C, Garbe C, et al. Combined vemurafenib and cobimetinib in BRAF-mutated melanoma. N Engl J Med. 2014;371:1867-76.

39. Larkin J, Lao CD, Urba WJ, McDermott DF, Horak C, Jiang J, Wolchok JD. Efficacy and Safety of Nivolumab in
Patients With BRAF V600 Mutant and BRAF Wild-Type Advanced Melanoma: A Pooled Analysis of 4 Clinical Trials. JAMA Oncol. 2015;1:433-40.

40. Hamid O, Robert C, Daud A, Hodi FS, Hwu WJ, Kefford R, Wolchok JD, Hersey P, Joseph RW, Weber JS, Dronca R, Gangadhar TC, Patnaik A, et al. Safety and tumor responses with lambrolizumab (anti-PD-1) in melanoma. N Engl J Med 2013;369:134-44.

41. Chen L, Han X. Anti-PD-1/PD-L1 therapy of human cancer: past, present, and future. J Clin Invest. 2015;125:3384-91.

42. Wherry EJ. T cell exhaustion. Nat Immunol. 2011; 12: 492-9.

43. Higgins JPT, Green S. Cochrane handbook for Systematic Reviews of intervention 4.2.6. The Cochrane Library. Chichester:John Wiley \& Sons, Ltd.; 2006.

44. Therasse P, Arbuck SG, Eisenhauer EA, Wanders J, Kaplan RS, Rubinstein L, Verweij J, Van Glabbeke M, van Oosterom AT, Christian MC, Gwyther SG. New guidelines to evaluate the response to treatment in solid tumors. European Organization for Research and Treatment of Cancer, National Cancer Institute of the United States, National Cancer Institute of Canada. J Natl Cancer Inst. 2000; 92:205-16.

45. Slim K, Nini E, Forestier D, Kwiatkowski F, Panis Y, Chipponi J. Methodological index for non-randomized studies (minors): development and validation of a new instrument. ANZ J Surg. 2003; 73:712-6.

46. Nyaga VN, Arbyn M, Aerts M. Metaprop: a Stata command to perform meta-analysis of binomial data. Arch Public Health. 2014; 72:39.

47. Zhang T, Cao L, Xie J, Shi N, Zhang Z, Luo Z, Yue D, Zhang Z, Wang L, Han W, Xu Z, Chen H, Zhang Y. Efficiency of CD19 chimeric antigen receptor-modified $\mathrm{T}$ cells for treatment of B cell malignancies in phase I clinical trials: a meta-analysis. Oncotarget. 2015;6:33961-71. doi: 10.18632/oncotarget.5582.

48. Parmar MK, Torri V, Stewart L. Extracting summary statistics to perform meta-analyses of the published literature for survival endpoints. Stat Med. 1998; 17:2815-34. 